\title{
Ultrastructure of Sheep Primordial Follicles Cultured in the Presence of Indol Acetic Acid, EGF, and FSH
}

\author{
Evelyn Rabelo Andrade, ${ }^{1}$ Poul Maddox-Hyttel, ${ }^{2}$ Fernanda Da Cruz Landim-Alvarenga, ${ }^{3}$ \\ José Roberto Viana Silva, ${ }^{4}$ Amauri Alcindo Alfieri, ${ }^{1}$ Marcelo Marcondes Seneda, ${ }^{1}$ \\ José Ricardo Figueiredo, ${ }^{5}$ and Ricardo Toniolli ${ }^{5}$ \\ ${ }^{1}$ Universidade Estadual de Londrina, DCV-CCA—UEL, 86051-990, Londrina, PR, Brazil \\ ${ }^{2}$ University of Copenhagen, Groennegaardsvej 7, 1870 Frederiksberg C, Denmark \\ ${ }^{3}$ Departamento de Reprodução Animal, Universidade Estadual de São Paulo, 18610-307 Botucatu, SP, Brazil \\ ${ }^{4}$ Universidade Federal do Ceará, 60020-181 Sobral, CE, Brazil \\ ${ }^{5}$ Medicina Veterinária, Universidade Estadual do Ceará, 60740-000 Fortaleza, CE, Brazil
}

Correspondence should be addressed to Marcelo Marcondes Seneda, mseneda@uel.br

Received 31 May 2010; Revised 6 September 2010; Accepted 5 November 2010

Academic Editor: Ali Honaramooz

Copyright (C) 2011 Evelyn Rabelo Andrade et al. This is an open access article distributed under the Creative Commons Attribution License, which permits unrestricted use, distribution, and reproduction in any medium, provided the original work is properly cited.

\begin{abstract}
The aim of this study was to investigate the ultrastructural characteristics of primordial follicles after culturing of sheep ovarian cortical slices in the presence of indol acetic acid (IAA), Epidermal Growth Factor (EGF), and FSH. To evaluate ultrastructure of primordial follicles cultured in MEM (control) or in MEM containing IAA, EGF, and FSH, fragments of cultured tissue were processes for transmission electron microscopy. Except in the control, primordial follicles cultured in supplemented media for $6 \mathrm{~d}$ were ultrastructurally normal. They had oocyte with intact nucleus and the cytoplasm contained heterogeneous-sized lipid droplets and numerous round or elongated mitochondria with intact parallel cristae were observed. Rough endoplasmic reticulum (RER) was rarely found. The granulosa cells cytoplasm contained a great number of mitochondria and abundant RER. In conclusion, the presence of IAA, EGF, and FSH helped to maintain ultrastructural integrity of sheep primordial follicles cultured in vitro.
\end{abstract}

\section{Introduction}

The use of oocytes from primordial follicles in assisted reproductive technologies could offer significant new avenues for the propagation of valuable animal stocks. As these follicles account for the vast majority of follicles (95\%) in the ovary [1], they can provide a great number of potentially viable oocytes for in vitro reproductive techniques, such as in vitro fertilization (IVF) and cloning. Technologies being developed for isolation [2,3], cryopreservation [4], and culture [5] of primordial follicles strive to prevent follicular atresia by optimizing the culture of these follicles in vitro.

Much research on the regulation of early follicular growth has focused on the control by hormones or growth factors. In cattle, the presence of FSH in the culture medium did not stimulate primordial follicle activation, also known as the gradual exit of ovarian follicles from the nongrowing pool [6], but it did increase oocyte and follicle diameter in goat primordial follicles cultured in vitro [7]. Treatment of isolated preantral follicles with follicle stimulating hormone (FSH) stimulated granulosa cell proliferation and eventually antrum formation [8-10]. Peptide growth factors like epidermal growth factor (EGF) are involved in the regulation of several ovarian processes [11] and have been shown to promote oocyte growth in goat primary follicles cultured in vitro [7]. The auxin, indol acetic acid (IAA) is found in blood and in several tissues, including lung, kidney, liver, and brain [12]. Previous studies from our team have demonstrated that sheep primordial follicles are successfully activated to grow in vitro after culturing in medium supplemented with 
$40 \mathrm{ng} / \mathrm{mL}$ IAA [13]. Moreover, the addition of IAA and EGF or EGF and FSH to the culture media were the most effective treatments to sustain the health and viability of growing sheep primordial follicles during in vitro culture [14].

In addition to our studies on primordial follicle activation in small ruminants [7], several other groups have demonstrated that a large percentage of primordial follicles can be activated in vitro after culture of ovarian cortical slices $[15,16]$. However, primary follicles obtained in vitro by this methodology failed to develop to secondary follicles even after 20 days in culture [17]. In the quoted investigations, follicular quality was assessed only by histological or immunohistochemical studies, and there is a great need to evaluate ultrastructural changes occurring in primordial follicles during activation in vitro. Hyttel and coworkers [18] reported a great number of ultrastructural and molecular alterations during oocyte development that can affect the oocyte capacity for fertilization and further development. Thus, ultrastructural studies are very important to evaluate the quality of oocytes enclosed in primordial follicles activated in vitro and to understand why these follicles do not continue their growth in vitro.

The objective of the present study was to investigate the ultrastructural characteristics of primordial follicles after culturing of sheep ovarian cortical slices for 6 days in the presence of IAA, EGF, and FSH.

\section{Materials and Methods}

2.1. Source of Ovaries. Ovaries $(n=8)$ from four cyclic adult (1 to 3 yr-old), nonpregnant Merino ewes (in good body condition) were collected at a local slaughterhouse. Ovaries were washed and transported in Phosphate Buffered Saline (PBS; Invitrogen, Carlsbad, CA, USA) to the laboratory within $1 \mathrm{~h}$ after slaughter at $37^{\circ} \mathrm{C}$.

2.2. General Culture Procedure and Media. In the laboratory, each pair of ovaries from a single animal was processed together. Fat and ligaments were removed, the ovary was cut in half and the medulla, large antral follicles and corpora lutea were removed. Following this, the ovarian cortex was divided into fragments of approximately $1 \times 1 \times 1 \mathrm{~mm}$. These pieces of ovarian cortex were cultured individually for $6 \mathrm{~d}$ in culture dishes (Sigma, MO, St Louis, USA) containing $1 \mathrm{~mL}$ aliquots of culture media at $39^{\circ} \mathrm{C}$ with $5 \% \mathrm{CO} 2$ in air. Every other day, the culture media was replaced with fresh media. The media used were (T1) Minimum Essential Medium (MEM; osmolarity, $300 \mathrm{mOsm} / \mathrm{L}$ and pH:7.2; Cultilab, Rio de Janeiro, RJ, Brazil) supplemented with ITS (insulin $6.25 \mu \mathrm{g} / \mathrm{mL}$, transferrin $6.25 \mu \mathrm{g} / \mathrm{mL}$ and selenium $6.25 \mathrm{ng} / \mathrm{mL}$; Invitrogen, Carlsbad, CA, USA), $0.23 \mathrm{mM}$ pyruvate (Invitrogen, Carlsbad, CA, USA), $2 \mathrm{mM}$ glutamine (Invitrogen, Carlsbad, CA, USA), 2 mM hypoxanthine (Sigma, St Louis, MO, USA), $1.25 \mathrm{mg} / \mathrm{mL}$ bovine serum albumin (BSA; Sigma, St Louis, MO, USA), and antibiotics $(100 \mu \mathrm{g} / \mathrm{mL}$ penicillin and $100 \mu \mathrm{g} / \mathrm{mL}$ streptomycin; Sigma, St Louis, MO, USA) (MEM+, control medium); (T2) $\mathrm{MEM}+$ plus IAA (40 ng/mL); (T3) MEM+ plus IAA + EGF
(100 ng/mL; Sigma, St Louis, MO, USA) or (T4) MEM+ plus $\mathrm{EGF}+\mathrm{FSH}(100 \mathrm{ng} / \mathrm{mL}$; porcine FSH, a gift from Dr. J. F. Beckers, Liège, Belgium). The media were compared using ovarian fragments from the same animal and each treatment was repeated four times.

The duration of culture was based on the time course of primordial follicle activation in sheep [13]. The treatments tested were based on the best results of culturing sheep preantral follicles in our laboratory [14] whereas concentrations of FSH and EGF were based on previous reports of culturing pig granulosa cells recovered from primary and secondary follicles [19] and bovine small preantral follicles [20]. The biological activity of both the porcine FSH and recombinant human EGF had previously been confirmed for small ruminant follicles [21] and granulosa cells [22], respectively.

\subsection{Qualitative and Quantitative Analysis of Primordial} Follicles by Transmission Electron Microscopy. After $6 \mathrm{~d}$ of culture in each media, ultrastructural analysis was performed on primordial follicles included in small cortical fragments. Briefly, the ovarian cortex were fixed in a solution containing $2 \%$ paraformaldehyde (Sigma, St Louis, MO, USA) and 2.5\% glutaraldehyde (Sigma, St Louis, MO, USA) in a $0.1 \mathrm{M}$ sodium cacodylate buffer ( $\mathrm{pH}$ 7.2; Electron Microscopy Sciences, Hatfield, PA, USA). After fixation, specimens were rinsed in the buffer and postfixed in 1\% osmium tetroxide (Electron Microscopy Sciences, Hatfield, PA, USA), $0.8 \%$ potassium ferricyanide (Electron Microscopy Sciences, Hatfield, PA, USA) and $5 \mathrm{mM} \mathrm{CaCl} 2$ (Electron Microscopy Sciences, Hatfield, PA, USA) in a $0.1 \mathrm{M}$ sodium cacodylate buffer (Electron Microscopy Sciences, Hatfield, PA, USA[23]). Subsequently, the samples were dehydrated in acetone and embedded in Spurr's epoxy resin (Ted Pella, Redding, CA, USA). Thin sections $(60 \mathrm{~nm})$ were prepared when the oocyte nucleus was present in the semithin sections. Semithin sections $(3 \mu \mathrm{m})$ were stained with toluidine blue (Ted Pella, Redding, CA, USA) while thin sections were then contrasted with uranyl acetate and lead citrate (Ted Pella, Redding, CA, USA), and examined using Philips CM100 transmission electron microscope.

Follicular normality was evaluated based on the integrity of the basement membrane, cellular density, presence or absence of pycnotic bodies, and oocyte integrity. Based on these variables, primordial follicles were classified as morphologically normal (healthy spherical or ovoid oocyte with uniform cytoplasm and granulosa cells surrounding the oocyte in a well organized layer without pycnotic nuclei) or degenerate (shrinkage of oocyte and/or pycnosis or swelling of the granulosa cells - [24]). The normal follicular pattern was based on team's previous works [24-26]. Overall, 40 follicles were evaluated for each treatment (10 follicles per replicate).

2.4. Statistical Analysis. Follicle viability was considered by the percentage of all preantral follicles that were morphologically normal; this comparison was done among all treatments. An arcsine transformation was done prior 


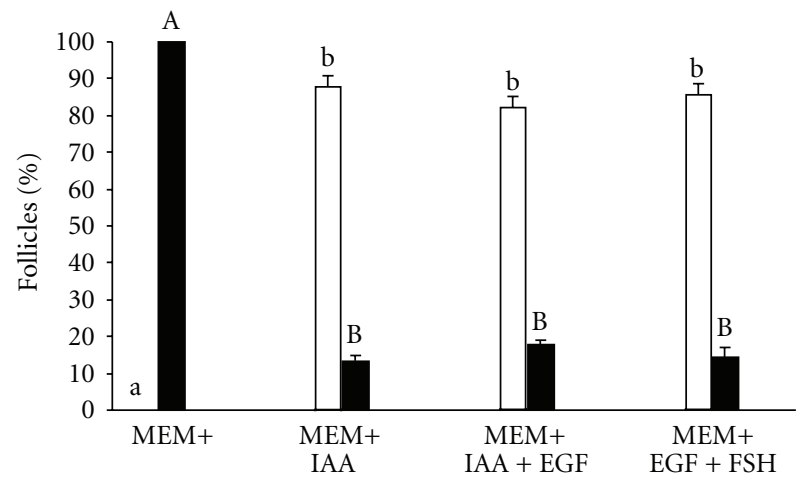

Figure 1: Mean $( \pm$ SEM $)$ percentages of preantral ovine follicles that were viable $(\square)$ or degenerated $(\square)$ in ovarian tissue after culture for $6 \mathrm{~d}$ in various treatments. ${ }^{\text {ab }}$ For viable follicles, treatments without a common superscript differ $(P<.05) .{ }^{\mathrm{AB}}$ For degenerated follicles, treatments without a common superscript differ $(P<.05)$.

to analysis. Repeated measures analysis of variance was used to evaluate the percentages of viable follicles. Pairwise comparisons were done using Tukey's procedure. All analyses were done with the Statistical Analysis System (SAS Institute, Cary, NC, USA) and $P<.05$ was considered significant.

\section{Results}

3.1. Quantitative Analysis of Follicular Viability. Based on transmission electron microscopy, on day 6 the percentages of viable cells in the cultures supplemented with $\mathrm{MEM}+\mathrm{IAA}, \mathrm{MEM}+\mathrm{IAA}+\mathrm{EGF}$, or in $\mathrm{MEM}+\mathrm{EGF}+\mathrm{FSH}$ were not significantly different from each other; however no normal follicles were found at culture in MEM+, as seen in Figure 1.

\subsection{Ultrastructure of Normal Primordial Follicles after Cul-} ture. The normal follicles consisted of a centrally located oocyte with intact nucleus and surrounded by a wellorganized layer of granulosa cells; the follicle boundary was demarcated by a basal lamina that presented homogeneous and fibrillar components. The basal lamina was intact in all follicles. The follicles were surrounded by dense connective tissue consisting of fibroblasts, smooth muscle cells, blood vessels, and prominent collagen bundles (Figure 2(a)). A large round oocyte nucleus, presenting intact nuclear envelope and sparse heterochromatic areas, occupied a central or eccentrioally position in the ooplasm (Figure 2(b)).

The ooplasm contained heterogeneous-sized lipid droplets (Figure 2(c)) and numerous round or elongated mitochondriawith intact parallel cristae (Figure 2(c)). Rough endoplasmic reticulum (RER) was rarely found, but long or short profiles of SER were spread throughout the oocyte cytoplasm and associated with the mitochondria (Figures 2(c) and 2(d)). A few Golgi apparatuses were observed in the ooplasm and occasionally they were associated with different sizes of vesicles, mitochondria, and smooth endoplasmic reticulum (Figure 2(e)).
The plasma membrane of the oocyte and granulosa cells was closely apposed, but no specific junctions were found between the two cell types. The oocyte surface presented numerous microvilli that made deep indentations of the plasma membrane of the adjacent granulosa cells (Figure 2(f)).

3.3. Ultrastructure of Degenerated Primordial Follicles after Culture. When cultured for 6 days in MEM+ alone, discreet changes in the ultrastructure of primordial follicles were observed. The changes included the presence of large vacuoles in the ooplasm and the presence of excessively clustered heterochromatin in the oocyte nucleus. The oocyte nucleus appeared miss shaped, presented an undulating nuclear envelope, and occasionally vacuole-like structures were noted in the nucleus (Figure 3).

\section{Discussion}

The present study assessed for the first time the ultrastructural characteristics of sheep primordial follicles in fragments of cortical tissue cultured in vitro in MEM+, MEM + IAA, $\mathrm{MEM}+\mathrm{IAA}+\mathrm{EGF}$, and in MEM + EGF + FSH for 6 days. In contrast to follicles cultured in control medium (MEM+), follicles that were cultured for 6 days in the presence of IAA, $\mathrm{IAA}+\mathrm{EGF}$ and EGF + FSH were ultrastructurally normal.

Culture conditions have a profound influence on follicle activation and viability. The molecular mechanisms of auxin action in plants were explained by Barbier-Brygoo [27]. Auxins bind to a soluble auxin-binding protein and the soformed complex consecutively associates with a transmembrane receptor causing, directly or indirectly, a variety of cell responses, including increased cell wall plasticity and cell water uptake, changed cell permeability and respiratory patterns, and acid nucleic metabolism [28]. However, the molecular mechanisms of auxin action in animal cells have not been elucidated. Very little is known about the interactions between IAA and EGF. According to Moon et al. [29], the interaction between IAA and EGF improved growth in various plants when compared to IAA per se. Conversely, IAA could bind to EGF or another molecule and potentiate its action in animals. Thus, IAA might bind to the animal growth factors present in the ovarian tissue, which in turn improve the action of these growth factors in animal cells, and still keep the cell permeability and respiratory patterns, which may explain the effectiveness of this treatment. In a study from our laboratory, both FSH and EGF stimulated an increase in follicle size by promoting oocyte growth in caprine preantral follicles [7]. An accelerated growth of bovine preantral follicles to the antral stage has been achieved over a period of as many as $28 \mathrm{~d}$ [30], with FSH and EGF enhancing follicular growth and development. Roy and Greenwald [31] suggested FSH increases DNA synthesis indirectly by stimulating EGF production by cultured hamster follicles, which then acts directly in a paracrine/autocrine manner.

Previous study from our group demonstrated that uncultured sheep primordial follicles exhibited a highly variable 


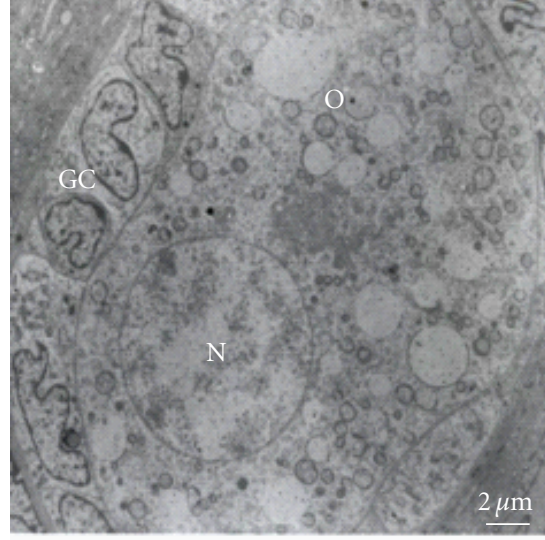

(a)

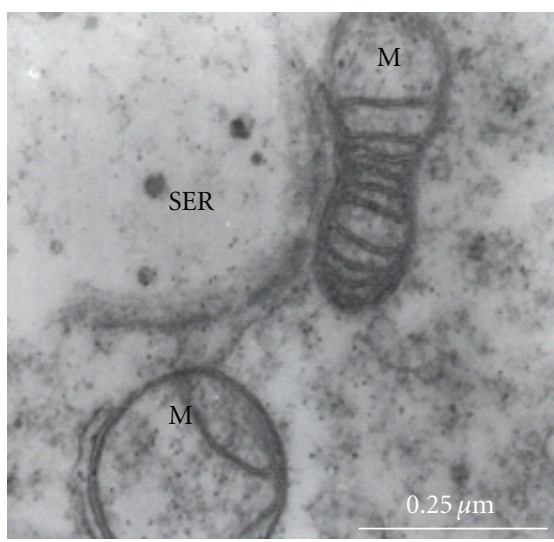

(d)

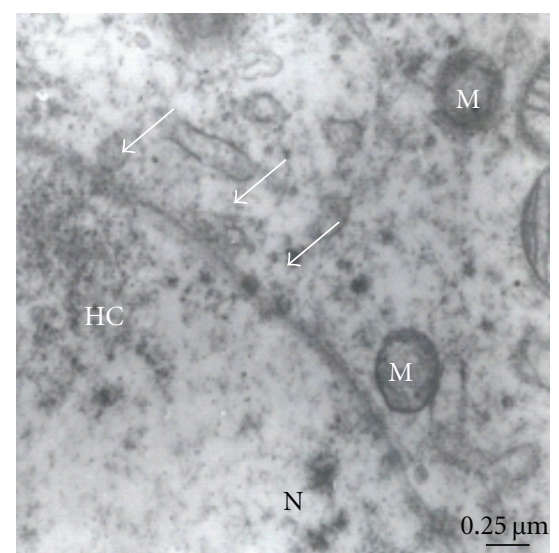

(b)

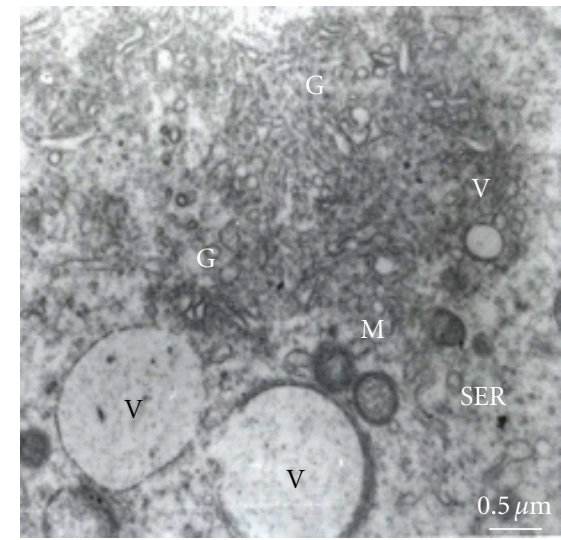

(e)

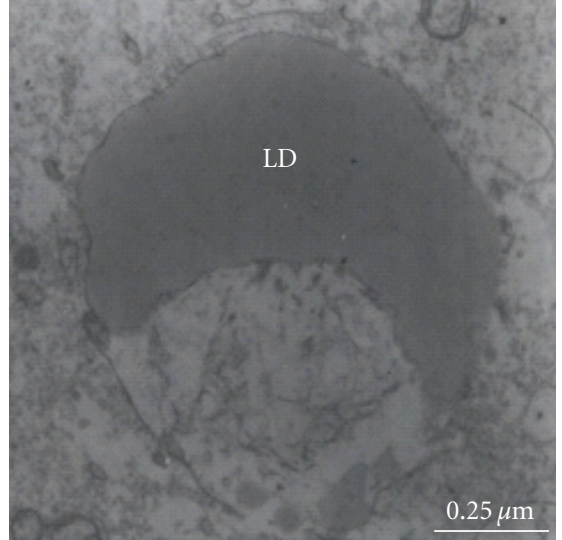

(c)

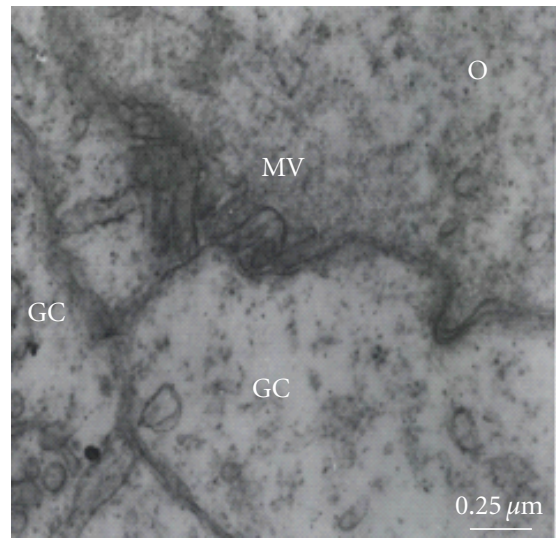

(f)

FIGURE 2: Electron micrography of a normal sheep preantral follicle showing: (a) a centrally located oocyte $(\mathrm{O})$ with intact nucleus (N), surrounded by an organized layer of granulosa cells (GC); (b) an intact nuclear envelope (arrows) between nucleus (N) and cytoplasm (C). Note the presence of heterochromatin (HC) in the nucleus and mitochondria (M) in the cytoplasm; (c) lipid droplets (LD); (d) round and elongated mitochondria (M) associated with profiles of smooth endoplasmic reticulum (SER); (e) Golgi apparatus (G) associated with different sizes of vesicles $(\mathrm{V})$, mitochondria $(\mathrm{M})$, and smooth endoplasmic reticulum (SER); (f) detail of the cortical region of the oocyte (O). Notice the presence of microvilli (MV) in direct contact with the granulosa cells (GCs).

number of vesicles and numerous large pleiomorphic mitochondria spread throughout the ooplasm. Both smooth and rough endoplasmic reticulum were present, either as isolated aggregations or as complex associations with mitochondria and vesicles. The follicles had sometimes a few microvilli and, occasionally, small amounts of zona pellucida material were visible. The cytoplasm of granulosa cells contained a great number of mitochondria and well-developed rough endoplasmic reticulum [32].

In cultured follicles, we observed numerous round or elongated mitochondria with intact parallel cristae in normal sheep primordial follicles. This finding is in good agreement with those reported by Lucci et al. [33] and Matos et al. [32], who examined goat and sheep preantral follicles, respectively. The observed pleiomorphic variations in mitochondrial shape possibly indicates the initiation of growth of the early oocyte [34]. Hooded mitochondria, typical of the ungulate oocyte after the growth phase [18], were not observed.

The ooplasm also presented SER and, to a lesser extend, RER associated with round or elongated mitochondria and vesicles. Such a feature is commonly observed in fresh preantral follicular oocytes of goats [35] and in sheep primordial follicular oocytes preserved in saline solution and TCM 199 [32]. In normal preantral follicular oocytes, the association of endoplasmic reticulum with mitochondria and vesicles suggests a mechanism for the transport of substrates into the mitochondria [23]. Furthermore, vesicles containing a variety of internal substances also appear to be evidence of transport to the perinuclear metabolic center from the oocyte surface or vice versa [36].

At least in bovine oocytes, the Golgi complex consists initially of lamellae arranged in a parallel fashion. However, as the oocyte enlarges a small number of vacuoles and granules appear in close association with the lamellae and at the late stages of growth the Golgi complex consists of a large conglomerate of vacuoles, granules, and lamellae [18].

The primordial follicular oocyte presented numerous slender microvilli that extends from the oocyte plasma membrane into indentations in the adjacent cells and presumably increases the absorptive capacity at the surface of the 


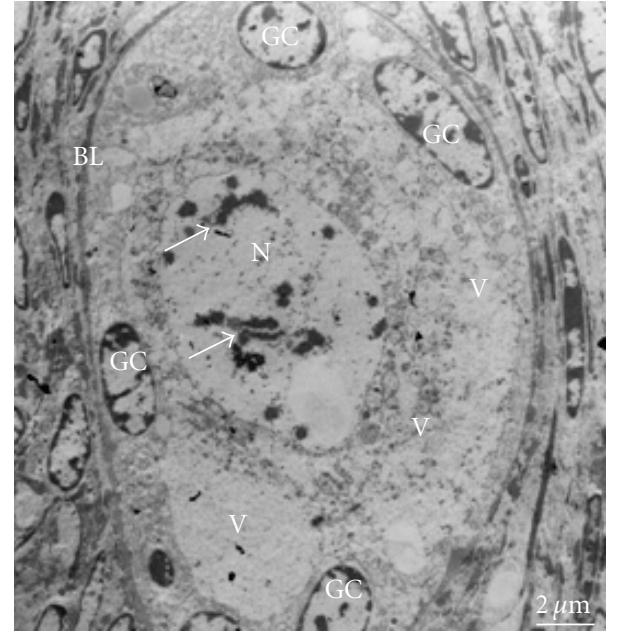

FIGURE 3: Electron micrography of a degenerated preantral follicle. Notice the presence of large vacuoles (V) in the oocyte cytoplasm and of excessive heterochromatic areas in the nucleus (arrows). GC: granulosa cells, $\mathrm{N}$ : nucleus, BL: basal lamina.

oocyte. Substances required for the oocyte metabolic needs could gain access to its cytoplasm by diffusion through the closely opposed membranes or they could be incorporated by endocytosis, as suggested by the presence of numerous coated pits and coated vesicles at the cortical ooplasm [33]. Besides that, cellular prolongations and gap junctions were observed between adjacent granulosa cells. Along with the oocyte growth phase, gap junctions are for the first time observed in bovine early secondary follicles [37] and in goats, this type of junctions were not observed between adjacent granulosa cells or between granulosa cells and oocyte in all developmental stages (i.e., primordial, primary and secondary) of preantral follicles [33], which may indicate species specific differences.

Primordial follicular oocytes cultured for $6 \mathrm{~d}$ in MEM+ exhibited an ooplasm with numerous vacuoles, as revealed by ultrastructural analysis. Van den Hurk et al. [38] and Devine et al. [39] demonstrated that oocytes with atretic signs contain numerous vacuoles in the ooplasm. Cytoplasmic vacuoles are also a characteristic sign of degeneration in granulosa [40] and cumulus cells [41] during degeneration in vivo and may represent extreme swelling, distension, and disruption of the endoplasmic reticulum [42]. On the other hand, vacuoles may also arise from distended mitochondria, as observed by Fuku et al. [43] in cryopreserved bovine oocytes. Silva et al. [23] reported that mitochondria exhibiting extensive swelling and disappearance of most of cristae as well endoplasmic reticulum enlarged in volume are the first sign of degeneration in preantral follicles. Distension of the endoplasmic reticulum was also indicative of degeneration in goat follicles conserved in vitro [23]. Degeneration of preantral follicles, especially primordial and primary, could be a consequence of improper growth activation [44]. After activation, organelle multiplication and an increase of the uptake of nutrient occurs [45]. The results present here suggest that MEM+ did not provide an appropriate environment for follicles to continue their normal development.

In conclusion, supplementing the in vitro culture media with IAA or either a combination of IAA and EGF or EGF and FSH maintained normal ultrastructural characteristics of sheep primordial follicles in ovarian tissue fragments for at least 6 days.

\section{Acknowledgments}

The authors wish to thank the Brazilian Institutes $\mathrm{CNPq}$, CAPES, and Fundação Araucária (FAP/PR) for financial support. E. R. Andrade is recipient of PRODOC/CAPES. A. A. Alfieri and M. M. Seneda are CNPq felowship.

\section{References}

[1] J. Saumande, "La folliculogénèse chez les ruminants," Recueil in Médicine Véterinarie, vol. 34, pp. 205-218, 1991.

[2] C. A. Amorim, A. P. R. Rodrigues, C. M. Lucci, J. R. Figueiredo, and P. B. D. Gonçalves, "Effect of sectioning on the number of isolated ovine preantral follicles," Small Ruminant Research, vol. 37, no. 3, pp. 269-277, 2000.

[3] C. M. Lucci, R. Rumpf, J. R. Figueiredo, and S. N. Báo, "Zebu (Bos indicus) ovarian preantral follicles: morphological characterization and development of an efficient isolation method," Theriogenology, vol. 57, no. 5, pp. 1467-1483, 2002.

[4] J. J. D. H. Celestino, R. R. D. Santos, C. A. P. Lopes et al., "Preservation of bovine preantral follicle viability and ultrastructure after cooling and freezing of ovarian tissue," Animal Reproduction Science, vol. 108, no. 3-4, pp. 309-318, 2008.

[5] G. Calongos, A. Hasegawa, S. Komori, and K. Koyama, "Comparison of urinary and recombinant follicle-stimulating hormone in in vitro growth, maturation, and fertilization of mouse preantral follicles," Fertility and Sterility, vol. 89, no. 5, pp. 1482-1489, 2008.

[6] J. E. Fortune, R. A. Cushman, C. M. Wahl, and S. Kito, "The primordial to primary follicle transition," Molecular and Cellular Endocrinology, vol. 163, no. 1-2, pp. 53-60, 2000.

[7] J. R. V. Silva, R. Van Den Hurk, M. H. T. De Matos et al., "Influences of FSH and EGF on primordial follicles during in vitro culture of caprine ovarian cortical tissue," Theriogenology, vol. 61, no. 9, pp. 1691-1704, 2004.

[8] R. E. Gore-Langton and S. A. J. Daniel, "Follicle-stimulating hormone and estradiol regulate antrum-like reorganization of granulosa cells in rat preantral follicle cultures," Biology of Reproduction, vol. 43, no. 1, pp. 65-72, 1990.

[9] P. L. Nayudu and S. M. Osborn, "Factors influencing the rate of preantral and antral growth of mouse ovarian follicles in vitro," Journal of Reproduction and Fertility, vol. 95, no. 2, pp. 349-362, 1992.

[10] S. K. Roy and B. J. Treacy, "Isolation and long-term culture of human preantral follicles," Fertility and Sterility, vol. 59, no. 4, pp. 783-790, 1993.

[11] K. Jewgenow, "Impact of peptide growth factors on the culture of small preantral follicles of domestic cats," Theriogenology, vol. 45, no. 4, pp. 889-895, 1996.

[12] J. M. Tusell, F. Artigas, and C. Sunol, "Comparison of high-performance liquid chromatography and gas 
chromatography-mass spectrometry for the analysis of indole3-acetic acid in brain tissue," Journal of Chromatography, vol. 306, pp. 338-344, 1984.

[13] E. R. Andrade, M. M. Seneda, A. A. Alfieri, J. A. Oliveira, J. R. Figueiredo, and R. Toniolli, "Efeito de diferentes concentrações de ácido 3-indol-acético na ativação e crescimento in vitro de folículos pré-antrais ovinos," Arquivo Brasileiro de Medicina Veterinária e Zootecnia, vol. 57, pp. 334339, 2005.

[14] E. R. Andrade, M. M. Seneda, A. A. Alfieri et al., "Interactions of indole acetic acid with EGF and FSH in the culture of ovine preantral follicles," Theriogenology, vol. 64, no. 5, pp. 11041113, 2005.

[15] S. A. Wandji, J. J. Eppig, and I. E. Fortune, "FSH and growth factors affect the growth and endocrine function in vitro of granulosa cells of bovine preantral follicles," Theriogenology, vol. 45, no. 4, pp. 817-832, 1996.

[16] O. Hovatta, "Cryopreservation and culture of human ovarian cortical tissue containing early follicles," European Journal of Obstetrics Gynecology and Reproductive Biology, vol. 113, pp. S50-S54, 2004.

[17] J. E. Fortune, S. Kito, S. A. Wandji, and V. Sršeň, "Activation of bovine and baboon primordial follicles in vitro," Theriogenology, vol. 49, no. 2, pp. 441-449, 1998.

[18] P. Hyttel, T. Fair, H. Callesen, and T. Greve, "Oocyte growth, capacitation and final maturation in cattle," Theriogenology, vol. 47, no. 1, pp. 23-32, 1997.

[19] D. E. Morbeck, W. L. Flowers, and J. H. Britt, "Response of porcine granulosa cells isolated from primary and secondary follicles to FSH, 8-bromo-cAMP and epidermal growth factor in vitro," Journal of Reproduction and Fertility, vol. 99, no. 2, pp. 577-584, 1993.

[20] S. Saha, M. Shimizu, M. Geshi, and Y. Izaike, "In vitro culture of bovine preantral follicles," Animal Reproduction Science, vol. 63, no. 1-2, pp. 27-39, 2000.

[21] M. A. Nowshari, J. F. Backers, and W. Holtz, "Superovulation of goats with purified pFSH supplemented with defined amounts of pLH," Theriogenology, vol. 43, no. 4, pp. 797-802, 1995.

[22] R. Behl and R. S. Pandey, "Effect of epidermal growth factor on steroidogenesis by caprine granulosa cells in culture: interaction with FSH," Small Ruminant Research, vol. 40, no. 1, pp. 57-62, 2001.

[23] J. R. V. Silva, S. N. Báo, C. M. Lucci et al., "Morphological and ultrastructural changes occurring during degeneration of goat preantral follicles preserved in vitro," Animal Reproduction Science, vol. 66, no. 3-4, pp. 209-223, 2001.

[24] J. R. V. Silva, M. A. L. Ferreira, S. H. F. Costa et al., "Degeneration rate of preantral follicles in the ovaries of goats," Small Ruminant Research, vol. 43, no. 3, pp. 203-209, 2002.

[25] C. M. Lucci, M. A. Kacinskis, L. H. R. Lopes, R. Rumpf, and S. N. Báo, "Effect of different cryoprotectants on the structural preservation of follicles in frozen zebu bovine (Bos indicus) ovarian tissue," Theriogenology, vol. 61, no. 6, pp. 1101-1114, 2004.

[26] M. H. T. Matos, I. B. Lima-Verde, J. B. Bruno et al., "Follicle stimulating hormone and fibroblast growth factor-2 interact and promote goat primordial follicle development in vitro," Reproduction, Fertility and Development, vol. 19, no. 5, pp. 677-684, 2007.
[27] H. Barbier-Brygoo, "Tracking auxin receptors using functional approaches," Critical Reviews in Plant Sciences, vol. 14, no. 1, pp. 1-25, 1995.

[28] R. Toniolli, J. Bussière, M. Courot, M. Magistrini, and Y. Combarnous, "Effect of indole-3-acetic acid (plant auxin) on the preservation at $15^{\circ} \mathrm{C}$ of boar semen for artificial inseminationEffet de l'auxine vegetale, l'acide 3-indole-acetique, sur la conservation du sperme de verrat pour l'insemination artificielle," Reproduction Nutrition Development, vol. 36, no. 5, pp. 503-511, 1996.

[29] A. M. Moon, M. I. Dyer, M. R. Brown, and D. A. Crossley, "Epidermal growth factor interacts with indole-3-acetic acid and promotes coleoptile growth," Plant and Cell Physiology, vol. 35, no. 8, pp. 1173-1177, 1994.

[30] C. G. Gutierrez, J. H. Ralph, E. E. Telfer, I. Wilmut, and R. Webb, "Growth and antrum formation of bovine preantral follicles in long-term culture in vitro," Biology of Reproduction, vol. 62, no. 5, pp. 1322-1328, 2000.

[31] S. K. Roy and G. S. Greenwald, "Hormonal requirements for the growth and differentiation of hamster preantral follicles in long-term culture," Journal of Reproduction and Fertility, vol. 87, no. 1, pp. 103-114, 1989.

[32] M. H.T. Matos, E. R. Andrade, C. M. Lucci et al., "Morphological and ultrastructural analysis of sheep primordial follicles preserved in $0.9 \%$ saline solution and TCM 199," Theriogenology, vol. 62, no. 1-2, pp. 65-80, 2004.

[33] C. M. Lucci, R. V. Silva, C. A. Carvalho, R. Figueiredo, and N. Báo, "Light microscopical and ultrastructural characterization of goat preantral follicles," Small Ruminant Research, vol. 41, no. 1, pp. 61-69, 2001.

[34] G. A. Perkins and T. G. Frey, "Recent structural insight into mitochondria gained by microscopy," Micron, vol. 31, no. 1, pp. 97-111, 2000.

[35] R. K. Sharma, A. K. Sawhney, and R. Vats, "Cytoplasmic fine structure of the primordial oocytes of goats," Indian Journal of Animal Science, vol. 64, pp. 1354-1356, 1994.

[36] A. T. Hertig and E. Adams, "Studies on human oocyte and its follicle, ultrastructure and its cytochemical observation on the pre ovulatory follicles," Journal of Cell Biology, vol. 34, pp. 647675, 1967.

[37] T. Fair, S. C. J. Hulshof, P. Hyttel, T. Greve, and M. Boland, "Oocyte ultrastructure in bovine primordial to early tertiary follicles," Anatomy and Embryology, vol. 195, no. 4, pp. 327336, 1997.

[38] R. Van Den Hurk, E. R. Spek, W. J. Hage, T. Fair, J. H. Ralph, and K. Schotanus, "Ultrastructure and viability of isolated bovine preantral follicles," Human Reproduction Update, vol. 4, no. 6, pp. 833-841, 1998.

[39] P. J. Devine, C. M. Payne, M. K. McCuskey, and P. B. Hoyer, "Ultrastructural evaluation of oocytes during atresia in rat ovarian follicles," Biology of Reproduction, vol. 63, no. 5, pp. 1245-1252, 2000.

[40] M. F. Hay, D. G. Cran, and R. M. Moor, "Structural changes occurring during atresia in sheep ovarian follicles," Cell and Tissue Research, vol. 169, no. 4, pp. 515-529, 1976.

[41] R. J. Assey, P. Hyttel, and N. Kanuya, "Oocyte structure in dominant and subordinate follicles in zebu cattle (Bos indicus)," Anatomy and Embryology, vol. 190, no. 5, pp. 461468, 1994.

[42] R. Tassell and J. P. Kennedy, "Early follicular development and atretic changes in the ovary of the lamb-fine structure and 
histochemistry," Australian Journal of Biological Sciences, vol. 33, no. 6, pp. 675-687, 1980.

[43] E. Fuku, L. Xia, and B. R. Downey, "Ultrastructural changes in bovine oocytes cryopreserved by vitrification," Cryobiology, vol. 32, no. 2, pp. 139-156, 1995.

[44] A. J. Mhawi, J. Kanka, and J. Motlík, "Follicle and oocyte growth in early postnatal calves: cytochemical, autoradiographical and electron microscopical studies," Reproduction, nutrition, development, vol. 31, no. 2, pp. 115-126, 1991.

[45] I. Rüsse, "Oogenesis in cattle and sheep," Bibliotheca Anatomica, vol. 24, pp. 77-92, 1983. 

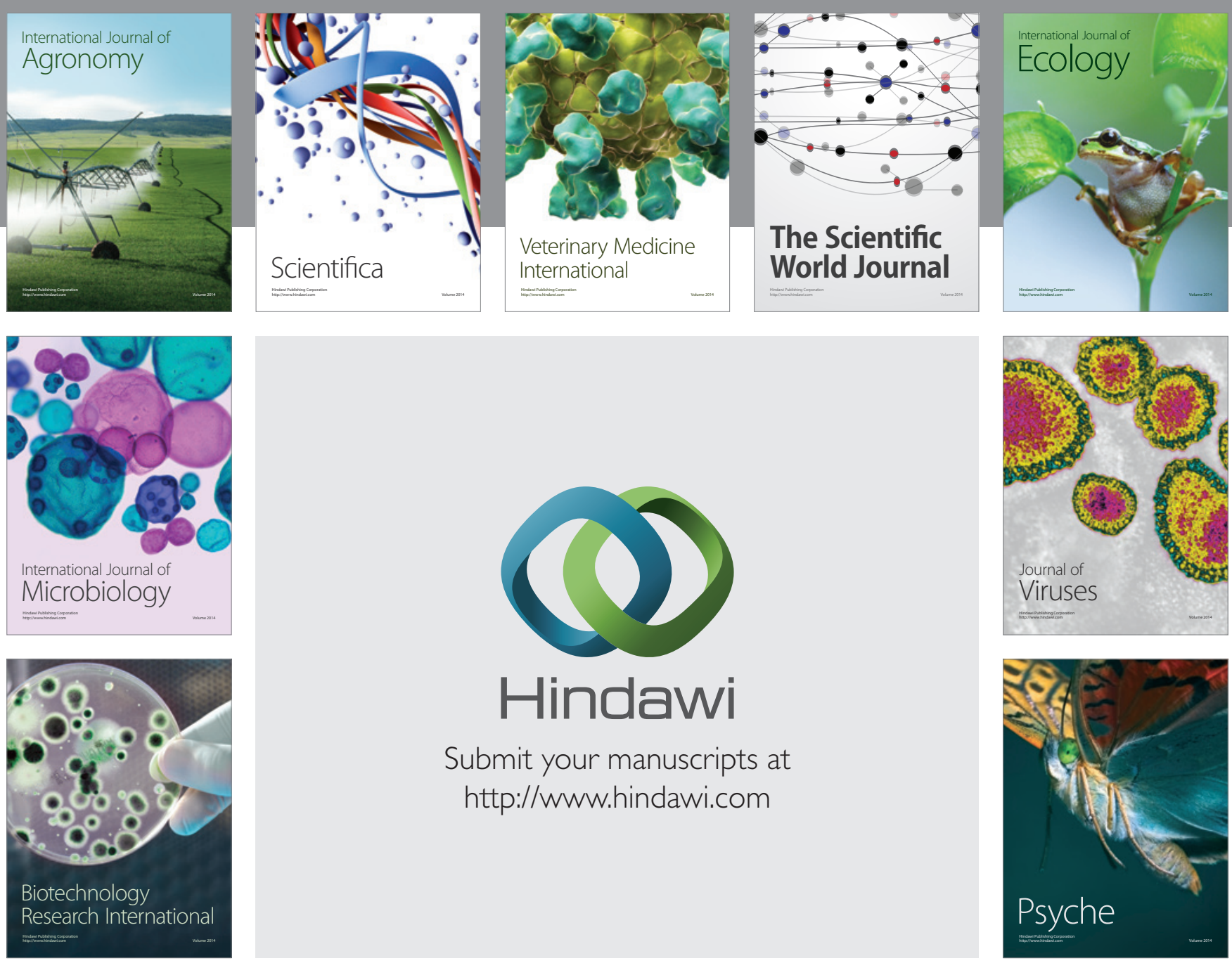

Submit your manuscripts at

http://www.hindawi.com
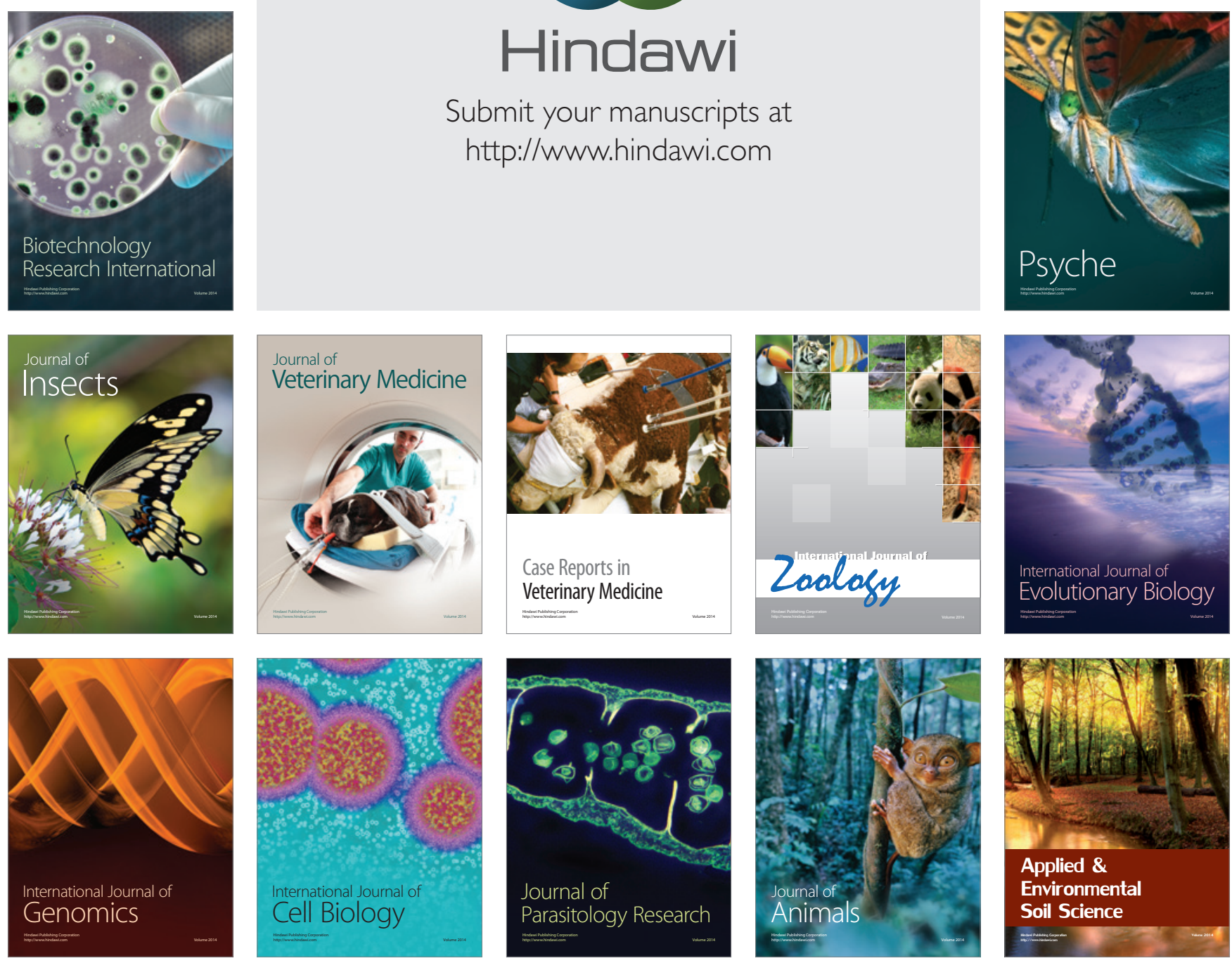